\title{
Chromosome 15 Abnormality in a Mentally Retarded Adult
}

\author{
SALLY KELLY, RYDIA ALMY, and ALICE DAGLE \\ From the Birth Defects Institute, New York State Department of Health, Albany, N.Y., U.S.A.
}

The trisomic chromosome in several examples of Patau's syndrome (Patau et al., 1960; Therman et al., 1961; Lubs, Koenig, and Brandt, 1961) has recently been identified with the late-replicating, distally labelled, $D_{1}$ (13) pair (Yunis, Hook, and Mayer, 1964b; Yunis et al., 1964a; Yunis and Hook, 1966; Giannelli, 1965; Giannelli and Howlett, 1966; Lee et al., 1966; Wilson et al., 1967; Bloom and Gerald, 1968). This report concerns a retarded adult with some manifestations of the $\mathrm{D}_{1}$ syndrome, in whom the abnormality involves a different $D$ chromosome.

\section{Case Report}

The patient, a 29-year-old white woman, has been in an institution since childhood with mental retardation. A report of a chromosome abnormality in her mentally retarded nephew prompted our investigation (A. Nurock, 1968, personal communication).

She was the fourth child, III.11 (Fig. 1), of unrelated

Received April 17, 1969. parents, who were 30 (mother) and 34 (father) years of age at her birth. Her birthweight was $3285 \mathrm{~g}$. after a full-term pregnancy and normal delivery. A left harelip, complete cleft palate, right talipes equinovalgus, overlapping right parietal suture, and a closed posterior fontanelle were noted. Milestones were delayed: she did not walk until 3 years; speech did not progress beyond responsive noises. She was underweight and undersized for her age. She was placed in a residential school for the retarded at the age of 8 years. Her IQ at the time was 33, with a mental age of 2 years 11 months (Merrill-Palmer scale).

She is a cheerful, active, restless woman who appears to understand simple statements and commands. She is short (153 cm.), solid (54 kg.), and kyphotic with sloping 8 shoulders. The facies are slightly asymmetrical and includeleft internal strabismus, occasional nystagmus, flat nose, and repaired harelip and cleft palate (Fig. 2). Head circumference is $488 \mathrm{~mm}$. The 1st and 5th fingers of both hands are short; there is ulnar deviation of both hands. She is neither hypertonic nor convulsive. Though the former talipes is well aligned, her gait is unsteady. Reflexes are brisk. There is no evidence of
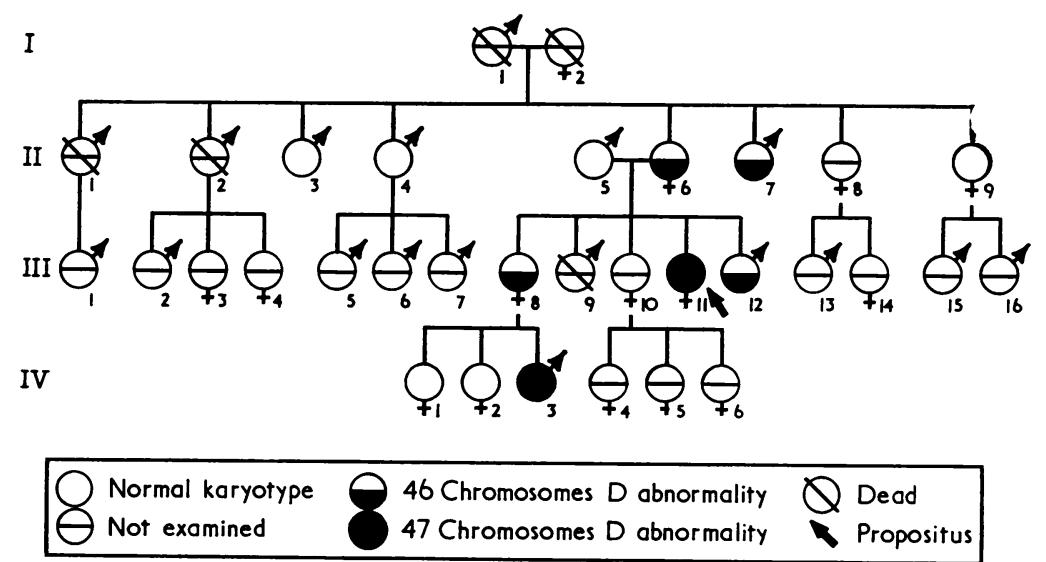

FIG. 1. Pedigree of patient, III.11. 


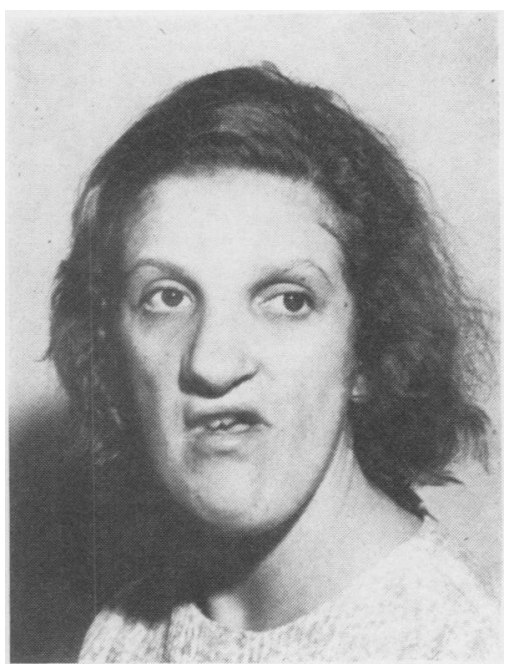

FIG. 2. Appearance of the patient at 29 years.

heart disease. Menarche was at 13 years. Her medical record on admission noted 'a double urethra and chronic pyelitis'.

The parents and three living sibs are healthy and of normal intelligence. The mother's face was irradiated for a skin condition in her youth. Her first pregnancy ended in an abortion, and later ones terminated in full-

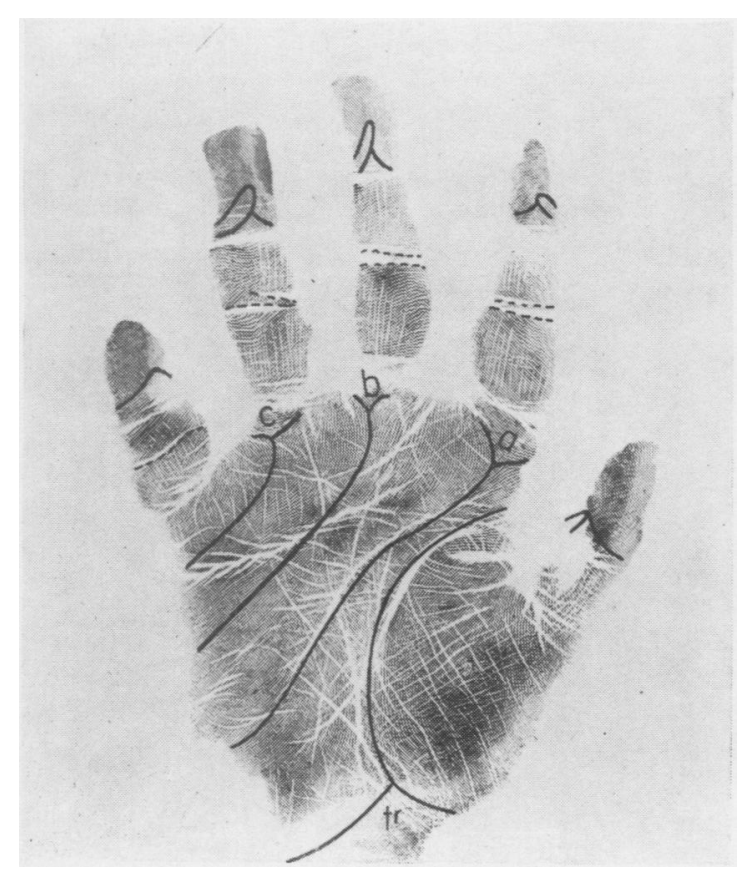

FIG. 3. Dermatoglyph of patient's left hand. term, living births. A normal brother died at 6 years from a meningococcus infection. The retarded nephew, a sister's son, is 6 years old, lacks the harelip, and is less retarded than his aunt at the same age, according to the family. The three children of another sister are normal. Other close relatives and their children are normal(Fig. 1).

\section{Dermatoglyphic Studies}

The digital pattern included one radial and seven ulnar loops, with arches on the right index and left 5th fingers. Axial triradii were in the $t^{\mathrm{r}}$ and $t$ positions in the left and right hands, respectively. The atd angles were not measurable, as the 4th interdigital areas were open bilaterally (the $d$ triradii were absent). There was a single flexion crease on the 5th finger of the left hand, and one on the 4th was incomplete (Fig. 3).

Palm prints of her parents, brother, III.12, two maternal uncles, II.4, II.7, and an aunt, II.8, revealed axial triradii in the $t$ position, atd angles of $50^{\circ}$ or less, normal interdigital patterns, and normal flexion creases.

\section{Cytogenetics and Autoradiography}

The patient's chromosome complement in leucocytes cultured by the method of Arakaki and Sparkes (1963) was 47 . The extra chromosome was small and submetacentric (Fig. 4) and was seen in the 26 metaphases examined. It was unlabelled in autoradiographs of leucocytes exposed to $1 \mu \mathrm{Ci} / \mathrm{ml}$. tritiated thymidine (Swartz Bio Research, Inc., specific activity $0.36 \mathrm{c} / \mathrm{m}$ mole) for 4 hours before mitoses were arrested (Fig. 5).

Cytogenetic studies of our patient's parents, brother, sister, III.8, and sister's family, including the retarded nephew, IV.3, were carried out elsewhere and are as yet unpublished (A. Nurock, 1968, personal communication). Her nephew's chromosome count was also 47; the extra chromosome was unmatched and similar to hers, resembling the $\mathrm{F}$ group pairs in size. Chromosome counts of her other relatives were 46. Karyotypes of her mother, II.6, brother, and sister, however, contained only 5 large acrocentrics, one apparently replaced by an unmatched chromosome, the size of the 17-18 pairs. The father's karyotype, II.5, was normal.

We confirmed the brother's abnormal karyotype, III.12, in another leucocyte culture (Fig. 4); autoradiographs revealed only one asynchronous, early-replicating (Schmid, 1963; German, 1964), unlabelled, $\mathrm{D}_{3}$ homologue (Yunis et al., 1964a). The unmatched chromosome was also unlabelled (Fig. 5).

Karyotypes of a maternal uncle, II.7, also lacked a large acrocentric and contained an unmatched submetacentric chromosome the size of one in the $\mathrm{E}$ group.

Karyotypes of the other maternal relatives, the uncles II.3 (L. Dallaire, 1968, personal communication), and II.4, and the two aunts, II.8, 9, were normal.

\section{Other Investigations}

Cellulose acetate electrophoresis of the patient's haemolysates revealed normal adult patterns of haemo- 


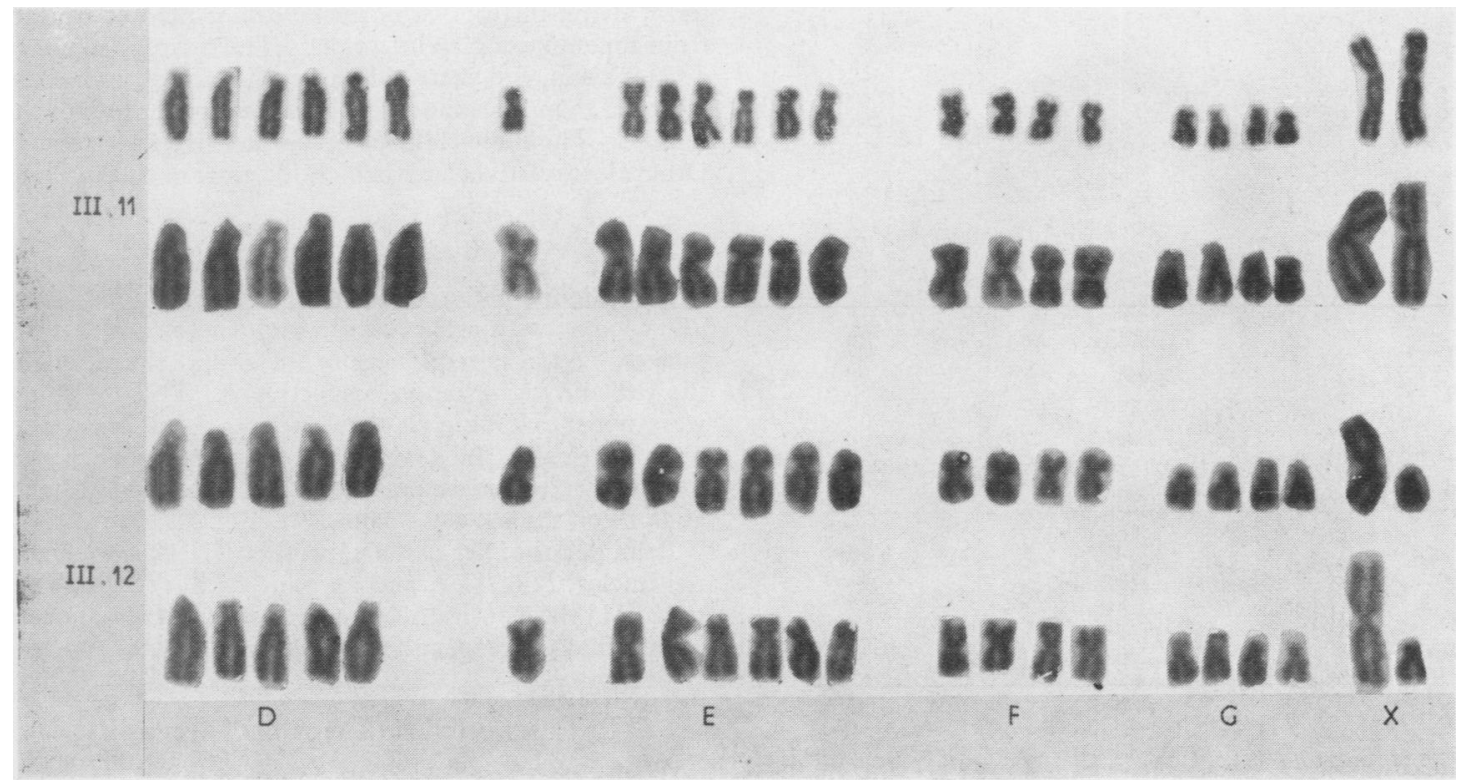

FIG. 4. Unmatched chromosomes in two partial karyotypes of patient, III.11, and her brother, III.12.

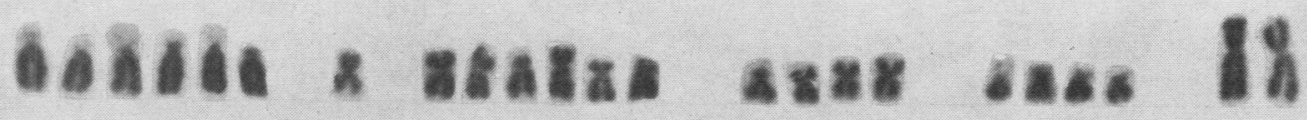

III 11
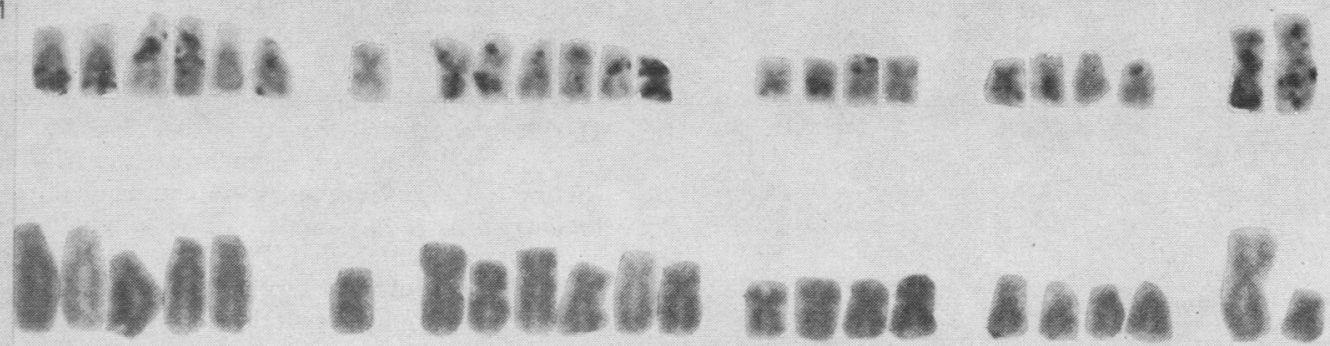

III 12
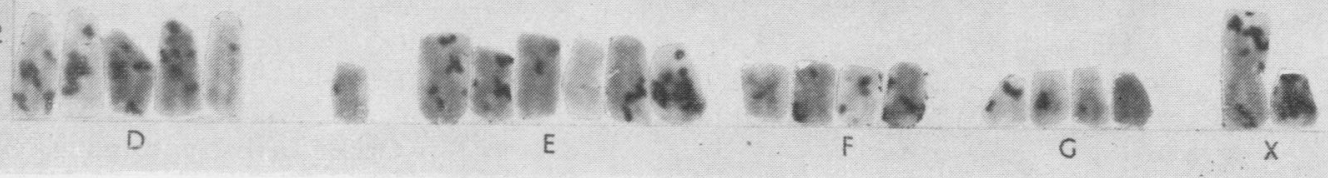

Fig. 5. Autoradiographs, showing labelling pattern of the unmatched chromosomes in karyotypes of the patient, III.11, and her brother III.12, and the 'missing' 15 homologue in III.12. 
globins $\mathrm{A}$ and $\mathrm{A}_{2}$ (Powars, Rohde, and Graves, 1964; Lee et al., 1966; Yunis and Hook, 1966; Bloom and Gerald, 1968) and of carbonic anhydrases B and C (Huehns et al., 1964a; Lee et al., 1966; Walzer et al., 1966; Wilson et al., 1967). Haemoglobin F was not detected by alkali denaturation nor by histochemical test (Huehns et al., 1964a; Pinkerton and Cohen, 1967). Nuclear projections were infrequent $(<1 \%)$ in the presence of a normal drumstick count (4\%) (Huehns, Lutzner, and Hecht, 1964b; Fine, Woo Wang, and Heath, 1965; Walzer et al., 1966).

Radial diffusion of her serum proteins revealed excessive concentrations of immunoglobins A $(640 \mathrm{mg}$. $/ 100$ ml.) and $M(180 \mathrm{mg} . / 100 \mathrm{ml}$.) and normal concentrations of immunoglobulin G (1730 mg./100 ml.) and caeruloplasmin $(27 \mathrm{mg} .100 \mathrm{ml}$.). Haptoglobins separated in a normal 2-1 pattern in disc electrophoresis.

Concentrations of the following enzymes were within normal ranges: leucocyte sulphatase and alkaline phosphatase, erythrocyte galactose-1-phosphate uridyl transferase, and serum creatine kinase.

\section{Discussion}

The labelling patterns of the D group chromosomes in the carrier brother's karyotype indicate that an early-labelling 15 homologue is missing. It is tempting to assign its apparent replacement to the small unmatched chromosome, which is also unlabelled. The aetiology of the latter is not clear, however: its small size precludes a pericentric inversion as its origin, unless a deletion accompanied it. There may have been a translocation between the $\mathrm{D}$ homologue and some other chromosome, but the latter is not identifiable in the otherwise normal karyotype. The two affected individuals a generation apart, then, may represent duplication deficiencies.

\section{Summary}

A small, submetacentric, 47th chromosome was found in the karyotype of a mentally retarded woman with skeletal abnormalities. A $\mathrm{D}_{15}$ chromosome was missing from the karyotype of her normal brother and was apparently replaced by a similar, small, unmatched chromosome. The pedigree included a retarded nephew and evidence for transmission of a balanced translocation through the maternal line. The clinical picture, dermatoglyphs, and indices of haematological, immunological, and biochemical maturity differed from those of the $\mathrm{D}_{1}$ (13) trisomy.
We thank Dr. Charles Greenberg, Director, Rome State School, New York State Department of Mental Hygiene, for calling our attention to the patient and her family history.

\section{REFERENCES}

Arakaki, D. T., and Sparkes, R. S. (1963). Microtechnique for culturing leukocytes from whole blood. Cytogenetics, 2, 57.

Bloom, G. E., and Gerald, P. S. (1968). Localization of genes on chromosomes 13: analysis of 2 kindreds. Amer. F. hum. Genet., 20, 495.

Fine, R. N., Woo Wang, M. Y. F., and Heath, C. W., Jr. (1965). Nuclear projections of neutrophils in the 13-15 trisomy syndrome. Pediatrics, 35, 712.

German, J. (1964). The pattern of DNA synthesis in the chromosomes of human blood cells. F. Cell Biol., $20,37$.

Giannelli, F. (1965). Autoradiographic identification of the D (1315) chromosome responsible for $D_{1}$ trisomic Patau's syndrome. Nature (Lond.), 208, 669.

- and Howlett, R. M. (1966). The identification of the chromosomes of the D group (13-15) Denver: An autoradiographic and measurement study. Cytogenetics, 5, 186.

Huehns, E. R., Hecht, F., Keil, J. V., and Motulsky, A. G. (1964a). Developmental hemoglobin anomalies in a chromosomal triplication: $\mathrm{D}_{1}$ trisomy syndrome. Proc. nat. Acad. Sci. (Wash.), 51, 89.

- Lutzner, M., and Hecht, F. (1964b). Nuclear abnormalities of the neutrophils in $D_{1}(13-15)$ trisomy syndrome. Lancet, 1, 589.

Lee, C. S. N., Boyer, S. H., Bowen, P., Weatherall, D. J., Rosenblum, H., Clark, D. B., Duke, J. R., Liboro, C., Bias, W., and Borgaonkar, D. S. (1966). The $D_{1}$ trisomy syndrome: Three subjects with unequally advancing development. Bull. Fohns Hopk. Hosp., 118, 374.

Lubs, H. A., Jr., Koenig, E. U., and Brandt, I. K. (1961). Trisomy 13-15: A clinical syndrome. Lancet, 2, 1001.

Patau, K., Smith, D. W., Therman, E., Inhorn, S. L., and Wagner, H. P. (1960). Multiple congenital anomaly caused by an extra autosome. ibid., 1, 790 .

Pinkerton, P. H., and Cohen, M. M. (1967). Persistence of hemoglobin $\mathrm{F}$ in $\mathrm{D} / \mathrm{D}$ translocation with trisomy 13-15 $\left(\mathrm{D}_{1}\right)$. F. Amer. med. Ass., 200, 647.

Powars, D., Rohde, R., and Graves, D. (1964). Foetal haemoglobin and neutrophil anomaly in the $\mathrm{D}_{\mathbf{1}}$-trisomy syndrome. Lancet, 1 , 1363.

Schmid, W. (1963). DNA replication patterns of human chromosomes. Cytogenetics, $2,175$.

Therman, E., Patau, K., Smith, D. W., and DeMars, R. I. (1961). The D trisomy syndrome and XO gonadal dysgenesis in two sisters. Amer. F. hum. Genet., 13, 193.

Walzer, S., Gerald, P. S., Breu, G., O'Neill, D., and Diamond, L. K. (1966). Hematologic changes in the $D_{1}$ trisomy syndrome. Pediatrics, 38, 419.

Wilson, M. G., Schroeder, W. A., Graves, D. A., and Katch, V. D. (1967). Hemoglobin variations in D-trisomy syndrome. New Engl. F. Med., 277, 953.

Yunis, J. J., Alter, M., Hook, E. B., and Mayer, M. (1964a). Familial D-D translocation. Report of a pedigree and DNA replication analysis. ibid., 271, 1133 .

_, and Hook, E. B. (1966). Deoxyribonucleic acid replication and mapping of the $D_{1}$ chromosome. A study of two patients with partial trisomy $\mathrm{D}_{1}$. Amer. F. Dis. Child., 111, 83.

- - , and Meyer, M. (1964b). Deoxyribonucleic-acid replication pattern of trisomy $D_{1}$. Lancet, 2, 935 .

\section{Addendum}

Since the manuscript was submitted, two other members of the family were found with normal chromosome complements, an aunt, II.8, and a sister, III.10. 